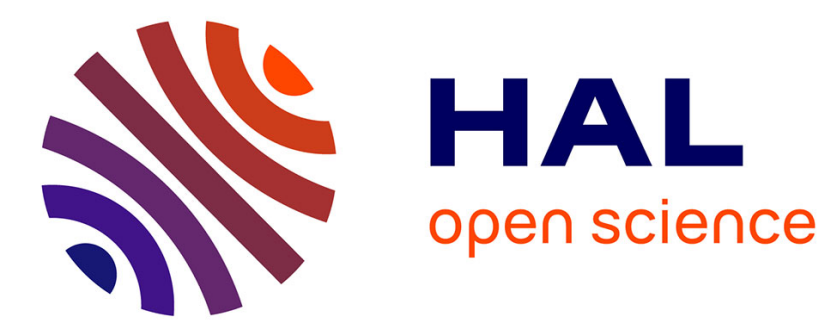

\title{
Hydrogenation-induced cerium valence change in CeNiZn
}

Sophie Tencé, Birgit Heying, Oliver Janka, Rainer Pöttgen, Bernard Chevalier

\section{To cite this version:}

Sophie Tencé, Birgit Heying, Oliver Janka, Rainer Pöttgen, Bernard Chevalier. Hydrogenationinduced cerium valence change in CeNiZn. Journal of Alloys and Compounds, 2017, 724, pp.515-519. 10.1016/j.jallcom.2017.07.038 . hal-01565192

\section{HAL Id: hal-01565192 \\ https://hal.science/hal-01565192}

Submitted on 19 Jul 2017

HAL is a multi-disciplinary open access archive for the deposit and dissemination of scientific research documents, whether they are published or not. The documents may come from teaching and research institutions in France or abroad, or from public or private research centers.
L'archive ouverte pluridisciplinaire HAL, est destinée au dépôt et à la diffusion de documents scientifiques de niveau recherche, publiés ou non, émanant des établissements d'enseignement et de recherche français ou étrangers, des laboratoires publics ou privés. 


\section{Hydrogenation-induced cerium valence change in CeNiZn}

Sophie Tencé ${ }^{a *}$, Birgit Heying ${ }^{\mathrm{b}}$, Oliver Janka ${ }^{\mathrm{b}}$, Rainer Pöttgen ${ }^{\mathrm{b}}$, Bernard Chevalier ${ }^{\mathrm{a}}$

a CNRS, Université de Bordeaux, ICMCB, UPR 9048, F-33600 Pessac, France

$b \quad$ Institut für Anorganische und Analytische Chemie, Universität Münster, Corrensstrasse 30, D-48149 Münster, Germany

* Corresponding authors: CNRS, Université de Bordeaux, ICMCB, UPR 9048, F33600 Pessac, France, Fax: +33-0540006634

E-mail addresses: sophie.tence@icmcb.cnrs.fr, pottgen@uni-muenster.de, bernard.chevalier@icmcb.cnrs.fr

\section{A R T ICLE IN F O}

Article history:

Received

Accepted

Available online

Keywords:

Cerium intermetallics

Zinc

Magnetic properties

Transport properties

Hydrogenation reaction

A B S T R A C T

Polycrystalline CeNiZn (ZrNiAl type, $P \overline{6} 2 m, a=715.6(4), c=388.4(2) \mathrm{pm}$ ) forms a new hydride $\mathrm{CeNiZnH}_{1.2(1)}$ under hydrogen exposure $(10 \mathrm{bar})$ at $423 \mathrm{~K}$. The resulting hydride crystallizes in a hexagonal structure $(P 6 / \mathrm{mmm})$ with the unit cell parameters $a=$ 433.19(2) and $c=424.37(2) \mathrm{pm}$. Thus, hydrogen atom insertion yields a structural 
transition from a $\mathrm{ZrNiAl}$ - to an $\mathrm{AlB}_{2}$-type structure with a high volume cell expansion of $+20.1 \%$. The magnetic, thermal and transport properties of $\mathrm{CeNiZnH}_{1.2(1)}$ were investigated. Susceptibility and specific heat measurements do not reveal magnetic order down to $1.8 \mathrm{~K}$ but most likely the presence of ferromagnetic correlations due to the proximity of a ferromagnetic order or a nonmagnetic atom disorder spin-glass state. Moreover, the cerium valence is modified from an intermediate to a trivalent state, a change that results from the decrease of the hybridization strength between conduction and $\mathrm{Ce}(4 f)$ electrons upon hydrogenation. Transport measurements also evidence a deviation from the typical resistivity behavior of metallic systems. Several scenarios are conceived to explain this change, in particular weak localization effect, knowing that it rarely occurs upon hydrogenation of intermetallics.

(C) 2017 Elsevier. All rights reserved.

\section{Introduction}

The equiatomic cerium intermetallics $\operatorname{Ce} T X(T=$ transition metal; $X=$ element of the $3^{\text {rd }}, 4^{\text {th }}$, or $5^{\text {th }}$ main group) cover more than 100 representatives with different crystal structures and broadly varying magnetic and electrical properties [1-3]. The physical properties of these materials depend on the valence electron concentration and the structure type. Several CeTX phases show pressure and / or temperature driven structural phase transitions along with distinct changes in the physical properties. These structure property relationships have recently been reviewed [1-3].

An interesting subgroup of the CeTX intermetallics concerns the CeTZn compounds. Zinc occupies the position typical for a $p$ element, underlining the covalent bonding within the two- or three-dimensional [TZn] networks. CeCuZn and CeAgZn [4] crystallize with the $\mathrm{KHg}_{2}$ type structure with random occupancy of the copper (silver) and zinc atoms on the mercury site. In contrast, CePtZn [5, 6] and CeAuZn [7, 8] show complete $\mathrm{Pt}(\mathrm{Au}) / \mathrm{Zn}$ ordering. Both compounds order antiferromagnetically below $\mathrm{T}_{\mathrm{N}}$ $=1.7 \mathrm{~K}[5-9]$. 
CeNiZn $[7,10]$ and CePdZn $[10,11]$ crystallize with the hexagonal ZrNiAl type. The nickel compound shows intermediate cerium valence. CePdZn is dimorphic. The hightemperature modification adopts the orthorhombic TiNiSi type. This has consequences on the magnetic ground state. The low-temperature modification shows no magnetic ordering down to $2 \mathrm{~K}$ while the high-temperature modification orders antiferromagnetically at $\mathrm{T}_{\mathrm{N}}=3.2 \mathrm{~K}$ [11]. Electronic structure calculations and the magnetic data point to larger $\mathrm{Ce}(4 f)-\mathrm{Pd}(4 d)$ hybridization for the low-temperature type phase.

CeRhZn (orthorhombic LaNiAl type) [12] is one of the remarkable CeTZn compounds. Its crystal structure contains two crystallographically independent cerium sites and temperature dependent magnetic susceptibility measurements indicate Pauli paramagnetism, in line with an almost tetravalent state for both sites.

The magnetic ground state of CeTX intermetallics can be effectively influenced through hydrogenation. The studies on $C \mathrm{Ce} T X \mathrm{H}_{\mathrm{x}}$ phases with $X=p$ element of the $3^{\text {rd }}, 4^{\text {th }}$ or $5^{\text {th }}$ main group are summarized in [1-3]. We have now included the zinc compounds into these systematic studies. Herein we report on the hydrogenation behavior of intermediate valent $\mathrm{CeNiZn}$ and describe the structural, magnetic, thermal and transport properties of the $\mathrm{CeNiZnH}_{\mathrm{x}}$ phase.

\section{Experimental}

\subsection{Synthesis}

Starting materials for the preparation of the CeNiZn precursor were cerium pieces (Sigma-Aldrich, > 99.9\%), nickel powder (Merck, 99+) and zinc granules (Merck, > 99.9 $\%)$. Pieces of the cerium ingot were first arc-melted [13] to a small button under an atmosphere of ca. 700 mbar. The argon was purified over titanium sponge (900 K), silica gel and molecular sieves. The cerium button, nickel powder and pieces of the zinc granules (36:32: 32 molar ratio) were then arc-welded in a tantalum ampoule. The latter was sealed in an evacuated quartz tube for oxidation protection, placed in a chamber furnace (Nabertherm P330) and heated to $1590 \mathrm{~K}$ within $6 \mathrm{~h}$. This high temperature was kept for $10 \mathrm{~min}$, followed by cooling to $920 \mathrm{~K}$ at a rate of $6 \mathrm{~K} \mathrm{~min}^{-1}$. The temperature was kept for another $6 \mathrm{~h}$ followed by cooling to room temperature within $2 \mathrm{~h}$. The 
polycrystalline sample could easily be separated from the container by mechanical fragmentation. CeNiZn is highly brittle and shows bright metallic lustre.

Hydrogen absorption experiments were performed by solid-gas reaction. An ingot of the CeNiZn precursor was crushed in small pieces prior to being introduced into a stainless steel container. The sample was activated under vacuum at $423 \mathrm{~K}$ for 2 hours and then exposed to a pressure of 10 bar of hydrogen gas at the same temperature for 1 day. The amount of hydrogen absorbed was determined volumetrically by monitoring pressure changes in a calibrated volume. After hydrogenation, we observe the decrepitation of the pieces into fine powder. The hydride is stable in air over months.

\subsection{X-Ray diffraction}

The polycrystalline CeNiZn precursor sample was checked by powder X-ray diffraction (XRD) (Enraf-Nonius FR552 Guinier camera) using $\mathrm{CuK}_{\alpha 1}$ radiation and $\alpha$ quartz $(a=491.30$ and $c=540.46 \mathrm{pm})$ as an internal reference substance. The refined lattice parameters $(a=715.6(4), c=388.4(2) \mathrm{pm})$ are in good agreement with earlier literature data $[7,10]$. The hydride $\mathrm{CeNiZnH}_{\mathrm{x}}$ was analysed by X-ray powder diffraction with a Philips1050-diffractometer using Bragg-Brentano geometry with $\mathrm{CuK}_{\alpha}$ radiation. The crystal structure was refined by the Rietveld method using the FullProf program [14].

\subsection{Physical property studies}

Magnetic properties of the samples were investigated using a MPMS-XL Squid magnetometer from Quantum Design. Measurements were performed on free powder in the temperature range $1.8-300 \mathrm{~K}$ and under magnetic fields up to $7 \mathrm{~T}$.

For the heat capacity measurements, one piece of the crushed pellet was fixed to a pre-calibrated heat capacity puck using Apiezon $\mathrm{N}$ grease to ensure thermal conductivity. Measurements were realized with a PPMS from Quantum design in the temperature range of 2.0 to $300 \mathrm{~K}$ under applied external fields of $0,0.1,1$ and $5 \mathrm{~T}$.

Resistivity measurements were carried out with a PPMS from 2 to $325 \mathrm{~K}$ using a ac four probe method. Powder of $\mathrm{CeNiZn}$ and $\mathrm{CeNiZnH}_{\mathrm{x}}$ was cold pressed to form pellets on which electrical contacts were glued with silver paint.

\section{Results and discussion}




\subsection{Structural aspects}

At $423 \mathrm{~K}$ and exposed to 10 bars of $\mathrm{H}_{2}$ gas, $\mathrm{CeNiZn}$ uptakes hydrogen till reaching a pressure plateau in around 35 min corresponding to an absorbed $\mathrm{H}$ amount of 1.2(1) H/f.u. (formula unit). Thus, this indicates the potential formation of the hydride $\mathrm{CeNiZnH}_{1.2(1)}$. The X-ray powder diffractograms of the precursor CeNiZn and the compound obtained after hydrogenation are shown in Fig. 1. The XRD pattern of CeNiZn is well indexed on the basis of the hexagonal $\mathrm{ZrNiAl}$-type structure (space group $P \overline{6} 2 m$ ), in agreement with data reported earlier in the literature $[7,10]$. In this structure, Ce atoms occupy the $3 f$ (0.41576 00$)$ site, Ni atoms $1 a(0) 00)$ and $2 d(2 / 31 / 3$ 1/2) sites and $\mathrm{Zn}$ the $3 g(0.76498$ 0 1/2) site, as determined from single crystal data. After hydrogen exposure, the compound displays a completely different pattern, confirming the effective hydrogen uptake in CeNiZn without any sign of decomposition. The diffractogram of the resulting hydride $\mathrm{CeNiZnH}_{1.2}$ is perfectly indexed with the hexagonal space group $P 6 / \mathrm{mmm}$, with the unit cell parameters $a=433.19(2)$ and $c=424.37(2) \mathrm{pm}$. The small extra peaks correspond to the presence of the $\mathrm{Ce}_{2} \mathrm{Ni}_{2} \mathrm{Zn}$ impurity already observed in the pristine compound as well as residual non-hydrogenated CeNiZn. A Rietveld refinement of the data was performed

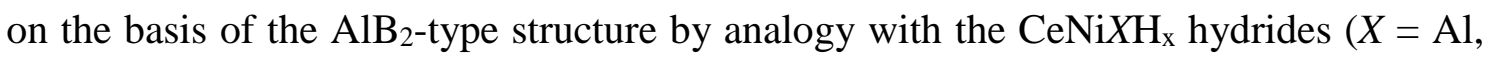
$\mathrm{Ga})$ that show similar X-ray patterns [15-17]. This Rietveld refinement $\left(\mathrm{R}_{\mathrm{Bragg}}=5.0 \%\right)$ is depicted in Fig. 1. The Ce atoms are located in the $1 a\left(\begin{array}{lll}0 & 0 & 0\end{array}\right)$ site whereas the $\mathrm{Ni}$ and $\mathrm{Zn}$ atoms are statistically distributed on the $2 d(1 / 32 / 31 / 2)$ site. However, it is noteworthy that the refinement of the structure considering an alternation of the $\mathrm{Ni}$ and $\mathrm{Zn}$ atoms within the $(a b)$-plane, i.e. with the LiBaSi-type structure $(P \overline{6} m 2)$, is only slightly worse since both elements have close $\mathrm{x}$-ray scattering factors. The simple $\mathrm{AlB}_{2}$-type structure is built up of face-sharing trigonal prisms of $\mathrm{Ce}$ atoms $\left[\mathrm{Ce}_{6}\right]$ filled either by $\mathrm{Ni}$ or $\mathrm{Zn}$ atoms in their centre. Thus, this structure contains $\left[\mathrm{Ce}_{3} \mathrm{Ni}\right]$ or $\left[\mathrm{Ce}_{3} \mathrm{Zn}\right]$ tetrahedra as potential interstitial sites for hydrogen atoms. It is noteworthy that $\left[\mathrm{Ce}_{3} \mathrm{Ni}\right]$ tetrahedra are also found in the ZrNiAl-type precursor CeNiZn. The positions of the hydrogen atoms could not be refined from X-ray data but we can assume that they are preferentially located in the $4 h$ sites $\left[\mathrm{Ce}_{3} \mathrm{Ni}\right]$ (or $\left[\mathrm{Ce}_{3} \mathrm{Zn}\right]$ ) tetrahedra. This hypothesis is based on neutron diffraction results obtained for the $\mathrm{CeNiInD}_{1.24}$ deuteride that report $\mathrm{D}$ atoms location in this position inducing short D-D interatomic distances of around 160 pm [18]. However, 
Shashikala et al. also mentioned the additional sites $6 k$ and $6 i$ for deuterium atoms in the CeNiAlD 3.2 deuteride crystallizing in the $\mathrm{AlB}_{2}$ type structure [19]. These tetrahedral interstices are formed by 2 atoms of $\mathrm{Ce}$ and 2 atoms of $\mathrm{Ni} / \mathrm{Zn}$ and are filled with a lower occupancy than the $4 h$ one. Thus, we can assume that the $4 h$ site is filled first, and then the $6 k$ and $6 i$ positions are occupied for higher H/D insertion rate. Neutron powder diffraction measurements will be needed to check this hypothesis for $\mathrm{CeNiZnH}_{1.2}$ and to determine more accurately the hydrogen composition within the structure.

The hydrogenation of CeNiZn induces a drastic increase of the molar volume from 0.0574 to $0.0690 \mathrm{~nm}^{3}$, i.e. an increase of $+20.1 \%$. Additionally, it yields a structural transition from the $\mathrm{ZrNiAl}$ to the $\mathrm{AlB}_{2}$-type structure. Interestingly, similar high volume expansion and structural change upon hydrogenation $(+19.7 \%)$ was also evidenced in the isotypic intermetallic uranium compound UNiZn [20]. In this case, the crystal structure of the resulting hydride $\mathrm{UNiZnH}_{2.3}$ was not unambiguously solved between the $\mathrm{AlB}_{2}$-type structure and a derivative of this structure with an ordering of the $\mathrm{Ni}$ and $\mathrm{Zn}$ atoms. But, the survival of the ZrNiAl-type structure was clearly ruled out the from x-ray diffraction analysis. In both $\mathrm{U}$ and Ce compounds, the observed structural modification is coherent with the high volume expansion. Indeed, the unit cell expansion exceeding 10-15\% induces this type of structural transition as for CeNiGa (low-temperature form) or CeNiAl, whereas lower volume increase $(<10-15 \%)$ keeps the initial $\mathrm{ZrNiAl}$ structure type as for CeNiIn [15-17].

The high volume expansion in the sequence $\mathrm{CeNiZn} \rightarrow \mathrm{CeNiZnH}_{1.2}$ results in increasing the interatomic distances in the structure, except for the shortest $\mathrm{M}-\mathrm{M}$ distance of $250 \mathrm{pm}, \mathrm{M}$ being $\mathrm{Ni}$ or $\mathrm{Zn}$ (see Table 1). In the precursor CeNiZn, the shortest distances, found between the $\mathrm{Ni}$ and $\mathrm{Zn}$ atoms, were equal to $257 \mathrm{pm}$. However, in the hydride, these distances still remain slightly longer than the sum of the covalent radii (240 pm for $\mathrm{Ni}+\mathrm{Zn})$. A spectacular effect concerns the strong augmentation of the $\mathrm{Ce}-\mathrm{Ce}$ distances from 371-389 to 424-433 pm. All these distances are much longer than those found in Ce metal (365 pm [21]) or in cerium hydride $\mathrm{CeH}_{2}$ (394 pm [22]). The Ce-M distances between $\mathrm{Ce}$ and $\mathrm{M}$ atoms also strongly increase upon hydrogenation, going from 289-322 pm in CeNiZn to $328 \mathrm{pm}$ in the hydride. These distances variations suggest 
that $f$ electrons could be more localized and the Ce valence state modified after hydrogen absorption.

\subsection{Magnetic, thermal and transport properties}

The temperature dependence of the magnetic susceptibility of CeNiZn and $\mathrm{CeNiZnH}_{1.2}$ measured in the field of $3 \mathrm{~T}$ is presented in Fig. 2. The curve of CeNiZn shows a rather temperature-independent behavior as reported earlier for this intermediatevalent cerium compound [7]. The small bump around $25 \mathrm{~K}$, not observed in ref [7], could be due to the presence of a small amount of the $\mathrm{Ce}_{2} \mathrm{Ni}_{2} \mathrm{Zn}$ impurity observed in XRD. On the contrary, the hydride displays much higher values of the susceptibility and follows a Curie-Weiss behavior above $30 \mathrm{~K}$ (see inset of Fig. 2). The downward curvature in inverse susceptibility below $30 \mathrm{~K}$ might be due to crystal-field effects. The linear fit of data in the temperature range $25-200 \mathrm{~K}$ gives an effective moment $\mu_{\text {eff }}=2.49 \mu_{\mathrm{B}} / \mathrm{Ce}$ atom and a paramagnetic Curie temperature $\theta_{\mathrm{p}}=-15 \mathrm{~K}$ (Table 2). The effective moment close to that of the free $\mathrm{Ce}^{3+}$ ion $\left(2.54 \mu_{\mathrm{B}}\right)$ suggests that the cerium is trivalent and that $\mathrm{Ni}$ atoms do not carry magnetic moments. This means that hydrogenation induces a cerium valence change from intermediate-valent to a trivalent state, which is coherent with the strong increase of the $\mathrm{Ce}-\mathrm{Ni}$ and $\mathrm{Ce}-\mathrm{Zn}$ interatomic distances from $\mathrm{CeNiZn}$ to $\mathrm{CeNiZnH}_{1.2}$.

For $\mathrm{CeNiZnH}_{1.2}$, the susceptibility measurement at $0.05 \mathrm{~T}$ (Fig. 3) shows an enhancement of $\chi(\mathrm{T})$ below $5 \mathrm{~K}$ but without clear evidence of any magnetic ordering down to $1.8 \mathrm{~K}$. The small anomaly around $8 \mathrm{~K}$ may be attributed to some impurity since no peak is visible at this temperature on the specific heat measurement (Fig. 4). However, the negative curvature of the magnetic isotherm $\mathrm{M}(\mathrm{H})$ at $1.8 \mathrm{~K}$ (inset of Fig. 3) may indicate the existence of ferromagnetic correlations. It is noteworthy that this behavior cannot be accounted for the presence of a small quantity of a ferromagnetic impurity. The magnetization at $1.8 \mathrm{~K}$ reaches almost $1 \mu_{\mathrm{B}} / \mathrm{Ce}$ atom at $7 \mathrm{~T}$. At higher temperatures the negative curvature of the $\mathrm{M}(\mathrm{H})$ isotherms progressively disappears and at $15 \mathrm{~K}$ the curve is linear. These observations suggest that, at low temperature, $\mathrm{CeNiZnH}_{1.2}$ could be close to a long-range ferromagnetic order or to a nonmagnetic atom disorder spin glass state. A spin glass behavior could arise from the atomic disorder on the $\mathrm{Ni} / \mathrm{Zn}$ site and on the $\mathrm{H}$ site that would yield a random exchange interaction between the $\mathrm{Ce}$ atoms. This was 
observed in the $\mathrm{AlB}_{2}$-type germanides $\mathrm{Ce}_{2} \mathrm{NiGe}_{3}$ and $\mathrm{Ce}_{2} \mathrm{CuGe}_{3}$ in which a random distribution of the $\mathrm{Ge}$ and $\mathrm{Ni}$ or $\mathrm{Cu}$ atoms on the $2 d$ crystallographic site is also reported $[23,24]$. The $\mathrm{M}(\mathrm{H})$ isotherms at low temperatures for these two germanides are very similar to those measured on $\mathrm{CeNiZnH}_{1.2}$. However, the absence of a peak in the ZFC curve of the hydride at 20 Oe (not shown here) does not allow us defining a freezing temperature $\mathrm{T}_{\mathrm{f}}$ as for $\mathrm{Ce}_{2} \mathrm{NiGe}_{3}\left(\mathrm{~T}_{\mathrm{f}}=3.5 \mathrm{~K}\right.$ [23]) or $\mathrm{Ce}_{2} \mathrm{CuGe}_{3}\left(\mathrm{~T}_{\mathrm{f}}=3 \mathrm{~K}\right.$ [24]).

The specific heat measurement in zero magnetic field shown in Fig. 4 clearly indicates the absence of a $\lambda$-peak characteristic of a magnetic order down to $2 \mathrm{~K}$. However, the $\mathrm{C}_{\mathrm{p}}(\mathrm{T})$ curve reveals a small upturn below $8 \mathrm{~K}$ which seems to reach a maximum around $2 \mathrm{~K}$. This maximum becomes more visible with increasing fields, especially at $5 \mathrm{~T}$. This behavior suggests the existence of a nonmagnetic atom disorder spin glass state or a ferromagnetic state. On the plot of the $\mathrm{C}_{\mathrm{p}} / \mathrm{T}$ versus $\mathrm{T}^{2}$, we observe a linear region above approximately $12 \mathrm{~K}$. The fit of the data with the formula $\mathrm{C}_{\mathrm{p}} / \mathrm{T}=\gamma+\beta \mathrm{T}^{2}$ between 12 and $24 \mathrm{~K}$ at zero field gives the values $\gamma=44 \mathrm{~mJ} \cdot \mathrm{mol}^{-1} \mathrm{~K}^{-2}$ and $\beta=0.478 \mathrm{~mJ} \cdot \mathrm{mol}^{-1} \mathrm{~K}^{-4}$ (Table 2 ). The $\beta$ coefficient, associated to the phonon contribution to the specific heat, gives an estimation of the Debye temperature $\theta_{\mathrm{D}}$ of $230 \mathrm{~K}$ (considering only the 3 non-hydrogen atoms since hydrogen atoms are usually involved in higher energy optical phonons modes). The moderate $\gamma$ value suggests that the Kondo effect is weak in the hydride, in agreement with the small paramagnetic Curie temperature $\theta_{\mathrm{p}}$. Nevertheless, below $12 \mathrm{~K}$, the $\mathrm{C}_{\mathrm{p}} / \mathrm{T}$ curve strongly increases, reaching a value of $1120 \mathrm{~mJ} \cdot \mathrm{mol}^{-1} \mathrm{~K}^{-2}$ at $2 \mathrm{~K}$. Such apparently large electronic coefficients $\gamma$ are usually found in heavy-fermions or in spin glass systems [25] as for example in the $\mathrm{Ce}_{2} \mathrm{NiGe}_{3}$ and $\mathrm{Ce}_{2} \mathrm{CuGe}_{3}$ spin glasses in which $\mathrm{C}_{\mathrm{p}} / \mathrm{T}$ even attains a maximum $[23,24]$. It was also observed in the hydrides $\mathrm{Ce}_{2} \mathrm{Ni}_{2} \mathrm{MgH}_{7.7}$ [26] and $\mathrm{CeNiGaH}_{1.1}$ [17], the last one crystallizing also in the $\mathrm{AlB}_{2}$-type structure. The rather high $\gamma$ value was associated to the existence of a strongly correlated system at low temperature in the former hydride and of a spin glass state in the latter one. However, in $\mathrm{CeNiZnH}_{1.2}$, this $\gamma$ value depends on the magnetic field since it is well reduced to 800 $\mathrm{mJ} . \mathrm{mol}^{-1} \mathrm{~K}^{-2}$ at $5 \mathrm{~T}$ (see inset of Fig 4). Therefore, it is reasonable to consider that this high $\gamma$ value is not ascribed to a heavy-fermion character manifestation since, usually, $\gamma$ is rather insensitive to the magnetic fields in heavy-fermion systems.

The resistivity measurements of the precursor CeNiZn and of the hydride are displayed on Fig. 5. The data were normalized to the value at $325 \mathrm{~K}$ because the use of 
compacted pellets for the measurements yields the presence of porosities and microcracks that hamper the accurate determination of $\rho(T)$. The resistivity of CeNiZn behaves as a normal metal as typically expected for an intermediate-valent Ce compound with a high spin fluctuations temperature $\mathrm{T}_{\text {sf. }}$ On the contrary, the electrical resistivity of $\mathrm{CeNiZnH}_{1.2}$ presents different characteristics: $\rho(\mathrm{T})$ rises continuously with decreasing temperature in the whole temperature range $1.8-325 \mathrm{~K}$ with a more pronounced augmentation below $25 \mathrm{~K}$. This behavior is not typical to that of a classical metal but more similar to that of a disordered Kondo system or a Kondo insulator as CeNiSn for example [27]. However, by plotting $\ln (\rho)$ versus $1 /$ T we do not clearly observe a linear region at low temperature allowing us to define a band gap $\mathrm{E}_{\mathrm{g}}$ (maybe due to the lack of pellet densification). Besides, a Kondo insulator state implies the absence of structural disorder and of a long-range magnetic order ground state [28], ground state which is not ruled out in our hydride. Thus, it is more likely that the drastic change in the transport properties originates from structural disorder. This could arise from the random distribution on the $\mathrm{Ni} / \mathrm{Zn}$ atoms on the $2 d$ site and on the partial filling of the $\mathrm{H}$ site. This hypothesis includes the case of a disordered Kondo lattice in which disorder hampers the establishment of the low-temperature coherent regime, regime below the Kondo temperature $T_{K}$ where the resistivity drops with decreasing temperature. In contrast, in the incoherent regime, the magnetic part of the resistivity diverges logarithmically as the temperature decreases. A similar resistivity curve as that of $\mathrm{CeNiZnH}_{1.2}$ was observed in the hydride $\mathrm{Ce}_{2} \mathrm{Ni}_{2} \mathrm{MgH}_{7.7}$ [26]. But as such a behavior was also reported for the isotypic compound $\mathrm{La}_{2} \mathrm{Ni}_{2} \mathrm{MgH}_{8}$ [29], this suggests that the Kondo effect is not directly responsible for the non-metallic character of $\mathrm{Ce}_{2} \mathrm{Ni}_{2} \mathrm{MgH}_{7.7}$. Another possibility to consider is the weak localization of electron waves induced by atomic disorder. In this case, the electron motion experiences numerous random scatterings on scattering centers. The resulting "circle-like manner" scattering paths give rise to interference phenomena which leads to an increase in the resistivity. This effect can be well reduced by the application of an external magnetic field. Therefore, further resistivity measurements under magnetic fields are planned in order to provide more evidences of weak localization effect in $\mathrm{CeNiZnH}_{1.2}$.

It is important to note that metal to non-metal transitions induced by hydrogenation occur rarely. Interestingly, such a transition was evidenced in the hydrides $\mathrm{MAlSiH}$ [30] 
and $M \mathrm{GaXH}[31](M=\mathrm{Ca}, \mathrm{Sr}, \mathrm{Ba} ; X=\mathrm{Si}, \mathrm{Ge}, \mathrm{Sn})$ which crystallize in a structure closely related to the $\mathrm{AlB}_{2}$-type. In those systems, the calculated density of states (DOS) clearly revealed an indirect band gap opening upon hydrogenation with Eg values between 0.1 and $0.8 \mathrm{eV}$. It was ascribed to the removal of the partly filled antibonding $\pi^{*}$ band in the metal having a predominantly $\mathrm{Ga}$ or $\mathrm{Al} p$ orbital character that yields an energetically low $\mathrm{Ga}(\mathrm{Al})-\mathrm{H}$ bonding band. Thus, it turns out that hydrogen captures electron density, leading to hydride formation with covalent $\mathrm{Ga}(\mathrm{Al})-\mathrm{H}$ bonding. However, it is unlikely that a similar scenario takes place in $\mathrm{CeNiZnH}_{1.2}$ since the Sommerfeld coefficient suggests a significant density of state at the Fermi level and thus the conservation of a metallic state.

\section{Conclusions}

The intermetallic CeNiZn forms the new hydride $\mathrm{CeNiZnH}_{1.2}$ upon exposure to 10 bar of $\mathrm{H}_{2}$ gas at $423 \mathrm{~K}$. The hydrogenation of CeNiZn induces a structural transition from a $\mathrm{ZrNiAl}$-type to an $\mathrm{AlB}_{2}$-type structure that goes along with a drastic unit cell volume expansion $(+20.1 \%)$ and a strong increase of the interatomic distances within the structure. As a result, the $\mathrm{Ce}(4 f)$ electrons are more localized, the hybridization strength between conduction and $f$ electrons decreases and the Ce valence changes from an intermediate to a trivalent state. According to magnetic and specific heat measurements, the hydride does not display magnetic order down to $2 \mathrm{~K}$ but is most likely close to a ferromagnetic order or to a spin-glass behavior as ground state. This second option could arise from the random distribution of the $\mathrm{Ni}$ and $\mathrm{Zn}$ atoms on the same Wyckoff position and on the partial filling of the $\mathrm{H}$ site inducing crystallographic disorder in the structure and thus the presence of competitive indirect RKKY (Rudermann-Kittel-Kasuya-Yosida) interactions between $\mathrm{Ce}$ atoms. Further magnetic and specific heat measurements at lower temperatures would be helpful to elucidate the ground state of $\mathrm{CeNiZnH}_{1.2}$.

Interestingly, hydrogen insertion also provokes a deviation from the classical metallic behaviour of the resistivity. In $\mathrm{CeNiZnH}_{1.2}$ it most likely results in atomic structural disorder leading to disordered Kondo lattice effect or weak localization of the electrons, as possible scenario. Further resistivity measurements under magnetic fields are planned in order to provide more evidences of weak localization effect in $\mathrm{CeNiZnH}_{1.2}$. Besides, it would be fruitful to better evidence the role of the structural disorder on the resistivity 
behavior notably. One possible way would be to modify the hydrogen amount in $\mathrm{CeNiZnH}_{\mathrm{x}}$ via different hydrogenation conditions. Such modifications of the transport properties, which are not often observed upon hydrogen insertion, can be interesting for applications as optical mirrors or hydrogen detector if they are reversible around room temperature.

\section{Acknowledgments}

Authors gratefully acknowledge R. Decourt for his help for electrical measurements.

\section{References}

[1] R. Pöttgen, B. Chevalier, Z. Naturforsch. 70b (2015) 289.

[2] R. Pöttgen, O. Janka, B. Chevalier, Z. Naturforsch. 71b (2016) 165.

[3] O. Janka, O. Niehaus, R. Pöttgen, B. Chevalier, Z. Naturforsch. $71 b$ (2016) 737.

[4] M. L. Fornasini, A. Iandelli, F. Merlo, M. Pani, Intermetallics 8 (2000) 239.

[5] R. Mishra, W. Hermes, R. Pöttgen, Z. Naturforsch. 62b (2007) 1581.

[6] S. K. Dhar, R. Kulkarni, H. Hidaka, Y. Toda, H. Kotegawa, T. C. Kobayashi, P. Manfrinetti, A. Provino, J. Phys.: Condens. Matter 21 (2009) 156001.

[7] W. Hermes, R. Mishra, U. Ch. Rodewald, R. Pöttgen, Z. Naturforsch. 63b (2008) 537.

[8] S. K. Dhar, Y. Aoki, B. Suemitsu, R. Miyazaki, A. Provino, P. Manfrinetti, J. Appl. Phys. 115 (2014) 17E113.

[9] L. Harriger, S. M. Disseler, J. Gunasekera, J. Rodriguez-Rivera, J. Pixley, P. Manfrinetti, S. K. Dhar, D. K. Singh, Phys. Rev. B 95 (2017) 041102.

[10] A. Iandelli, J. Alloys Compd. 182 (1992) 87.

[11] W. Hermes, R. Mishra, H. Müller, D. Johrendt, R. Pöttgen, Z. Anorg. Allg. Chem. 635 (2009) 660.

[12] W. Hermes, A. F. Al Alam, S. F. Matar, R. Pöttgen, Solid State Sci. 10 (2008) 1895.

[13] R. Pöttgen, T. Gulden, A. Simon, GIT Labor-Fachzeitschrift 43 (1999) 133.

[14] J. Rodriguez-Carvajal, Phys. B 192 (1993) 55.

[15] B. Chevalier, M. Pasturel, J.-L. Bobet, R. Decourt, J. Etourneau, O. Isnard, J. Sanchez Marcos, J. Rodriguez Fernandez, J. Alloys Comp. 383 (2004) 4.

[16] J.-L. Bobet, B. Chevalier, B. Darriet, M. Nakhl, F. Weill, J. Etourneau, J. Alloys Comp. 317 (2001) 67.

[17] B. Chevalier, J. Sanchez Marcos, J. Rodriguez Fernandez, M. Pasturel, F. Weill, Phys. Rev. B 71 (2005) 214437. 
[18] V. A. Yartys, R. V. Denys, B. C. Hauback, H. Fjellvag, I. I. Bulyk, A. B. Riabov, Ya. M. Kalychak, J. Alloys Comp. 330 (2002) 132.

[19] K. Shashikala, A. Sathyamoorthy, P. Raj, W. B. Yelon, S. K. Malik, J. Alloys Comp. 438 (2007) 84.

[20] S. Mašková, S. Daniš, K. Miliyanchuk, O. Stelmakhovych, B. Vondráčková, A.V. Kolomiets, L. Havela, J. Alloys Compd. 646 (2015) 885.

[21] E. T. Teatum, K. A. Gschneidner Jr, J. T. Waber, Los Alamos Report, LA 4003, University of California 58 (1968).

[22] P. Knappe, H. Müller, Z. Anorg. Allg. Chem. 487 (1982) 63.

[23] D. Huo, J. Sakurai, T. Kuwai, Y. Isikawa, Q. Lu, Phys. Rev. B 64 (2001) 224405.

[24] Cheng Tien, Chung Hsing Feng, Ching Shui Wur, Jenq Jong Lu, Phys. Rev. B 61 (2000) 12151.

[25] K. A. Gschneidner, J. Tang, S. K. Dhar, A. Goldman, Physica B 163 (1990) 507.

[26] B. Chevalier, A. A. Krolak, J.-L. Bobet, E. Gaudin, F. Weill, W. Hermes, R. Pöttgen, Inorg. Chem. 47 (2008) 10419.

[27] T. Takabatake, F. Teshima, H. Fujii, S. Nishigori, T. Suzuki, T. Fujita, Y. Yamaguchi, J. Sakurai, D. Jaccard, Phys. Rev. B 41 (1990) 9607.

[28] S. Doniach, Castor Fu, S. A. Trugman, Phys. Rev. B 199-200 (1994) 450.

[29] J. N. Chotard, Y. Filinchuk, B. Revaz, K. Yvon, Angew. Chem. Int. Ed. 45 (2006) 7770 .

[30] M. H. Lee, T. Bjorling, B. C. Hauback, T. Utsumi, D. Moser, D. Bull, D. Noreus, O. F. Sankey, U. Häussermann, Phys. Rev. B 78 (2008) 195209.

[31] M. J. Evans, G. P. Holland, F. J. Garcia-Garcia, U. Häussermann, J. Am. Chem. Soc. 130 (2008) 12139. 
Table 1. Interatomic distances (pm) of CeNiZn and $\mathrm{CeNiZnH}_{1.2}$. For CeNiZn, Ni1 and Ni2 atoms are in positions $1 a\left(\begin{array}{lll}0 & 0\end{array}\right)$ and $2 d(2 / 31 / 31 / 2)$ respectively.

\begin{tabular}{|c|c|c|c|c|c|c|}
\hline \multirow{2}{*}{$\begin{array}{l}\text { CeNiZn } \\
\mathrm{Ce}\end{array}$} & \multicolumn{6}{|c|}{$\mathrm{CeNiZnH}_{1.2}$} \\
\hline & $\mathrm{Ni2} \quad \mathrm{x} 4$ & $289.45(6)$ & $\mathrm{Ce}$ & $\mathrm{Ni} / \mathrm{Zn}$ & $\mathrm{x} 12$ & $327.98(1)$ \\
\hline & Ni1 $x 1$ & $296.6(1)$ & & $\mathrm{Ce}$ & $\mathrm{x} 2$ & $424.37(2)$ \\
\hline & $\mathrm{Zn} \quad \mathrm{x} 2$ & $315.95(9)$ & & $\mathrm{Ce}$ & x6 & $433.19(2)$ \\
\hline & $\mathrm{Zn} \quad \mathrm{x} 4$ & $322.66(9)$ & & & & \\
\hline & $\mathrm{Ce} \quad \mathrm{x} 4$ & $371.5(1)$ & $\mathrm{Ni} / \mathrm{Zn}$ & $\mathrm{Ni} / \mathrm{Zn}$ & $\mathrm{x} 3$ & $250.10(1)$ \\
\hline & Ce $\mathrm{x} 2$ & $388.7(1)$ & & $\mathrm{Ce}$ & x6 & $327.98(1)$ \\
\hline \multirow[t]{3}{*}{ Ni1 } & $\mathrm{Zn} \quad \mathrm{x} 6$ & $256.66(6)$ & & $\mathrm{Ni} / \mathrm{Zn}$ & $\mathrm{x} 2$ & $424.37(2)$ \\
\hline & $\mathrm{Ce} \quad \mathrm{x} 3$ & 296.56(9) & & $\mathrm{Ni} / \mathrm{Zn}$ & $x 6$ & 433.19(1) \\
\hline & Ni1 $x 2$ & $388.7(1)$ & & $\mathrm{Ni} / \mathrm{Zn}$ & x6 & $492.59(2)$ \\
\hline \multirow[t]{3}{*}{$\mathrm{Ni} 2$} & $\mathrm{Zn} \quad \mathrm{x} 3$ & $279.5(1)$ & & & & \\
\hline & Ce x6 & $289.45(8)$ & & & & \\
\hline & $\mathrm{Ni} 2 \times 2$ & $388.7(1)$ & & & & \\
\hline \multirow[t]{6}{*}{$\mathrm{Zn}$} & Ni1 $\quad x 2$ & $256.66(6)$ & & & & \\
\hline & $\mathrm{Ni} 2 \mathrm{x} 2$ & 279.51(9) & & & & \\
\hline & $\mathrm{Zn} \quad \mathrm{x} 2$ & 290.4(1) & & & & \\
\hline & $\mathrm{Ce} \quad \mathrm{x} 2$ & $315.95(9)$ & & & & \\
\hline & $\mathrm{Ce} \quad \mathrm{x} 4$ & $322.66(9)$ & & & & \\
\hline & $\mathrm{Zn} \quad \mathrm{x} 2$ & $388.7(1)$ & & & & \\
\hline
\end{tabular}

Table 2. $\mu_{\mathrm{eff}}, \theta_{\mathrm{p}}, \gamma$ and $\beta$ fitting values of $\mathrm{CeNiZn}$ and $\mathrm{CeNiZnH}_{1.2}$ obtained as explained in the text from the Curie-Weiss fit of the susceptibility curve and from the low-temperature specific heat measurement. The data for CeNiZn are taken from ref [5].

\begin{tabular}{lcccc}
\hline & $\begin{array}{c}\mu_{\text {eff }} \\
\left(\mu_{\mathrm{B}}\right)\end{array}$ & $\begin{array}{c}\theta_{\mathrm{p}} \\
(\mathrm{K})\end{array}$ & $\begin{array}{c}\gamma \\
\left(\mathrm{mJ}_{\mathrm{mol}}{ }^{-1} \cdot \mathrm{K}^{-2}\right)\end{array}$ & $\begin{array}{c}\beta \\
\left(\mathrm{mJ}^{\mathrm{mol}} \mathrm{mol}^{-1} \cdot \mathrm{K}^{-4}\right)\end{array}$ \\
\hline CeNiZn & 0.29 & -2.8 & - & - \\
CeNiZnH$_{1.2}$ & 2.49 & -15 & 44 & 0.478 \\
\hline
\end{tabular}




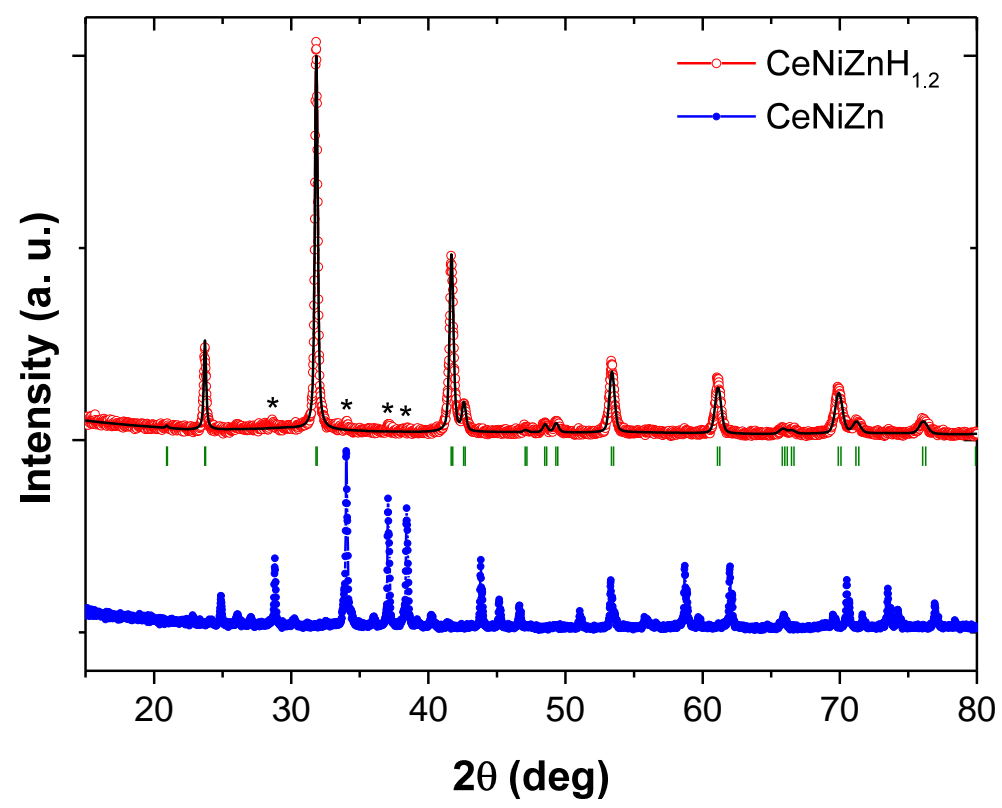

Fig. 1. X-ray powder diffraction patterns of $\mathrm{CeNiZn}$ and $\mathrm{CeNiZnH}_{1.2}$. Indexation of the pattern on the basis of the $\mathrm{AlB}_{2}$-type structure is indicated for the hydride and Rietveld refinement is shown by a solid line. Stars symbols indicate the main visible peaks of the residual pristine compound.

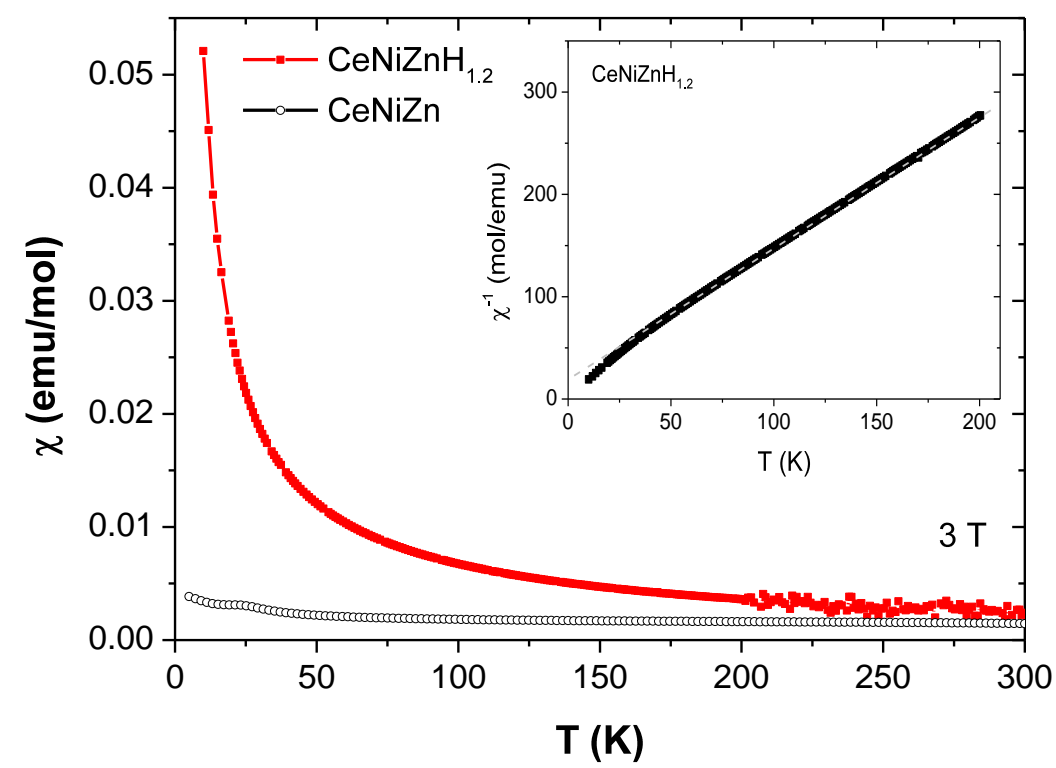

Fig. 2. Temperature dependence of the magnetic susceptibility of $\mathrm{CeNiZn}$ and $\mathrm{CeNiZnH}_{1.2}$ measured at $3 \mathrm{~T}$. Inset: Temperature dependence of the inverse of the magnetic susceptibility of the hydride with the Curie-Weiss fit in dotted line. 


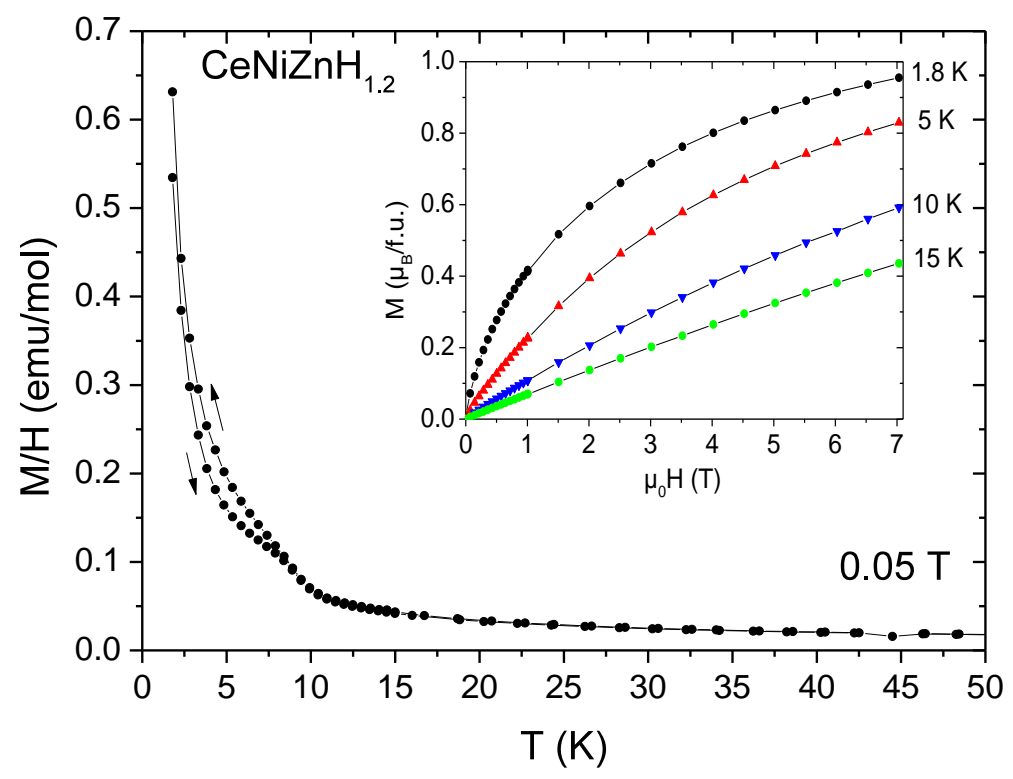

Fig. 3. Temperature dependence of the susceptibility of $\mathrm{CeNiZnH}_{1.2}$ measured at $0.05 \mathrm{~T}$. Inset: Magnetization isotherms of $\mathrm{CeNiZnH}_{1.2}$ at various temperatures.

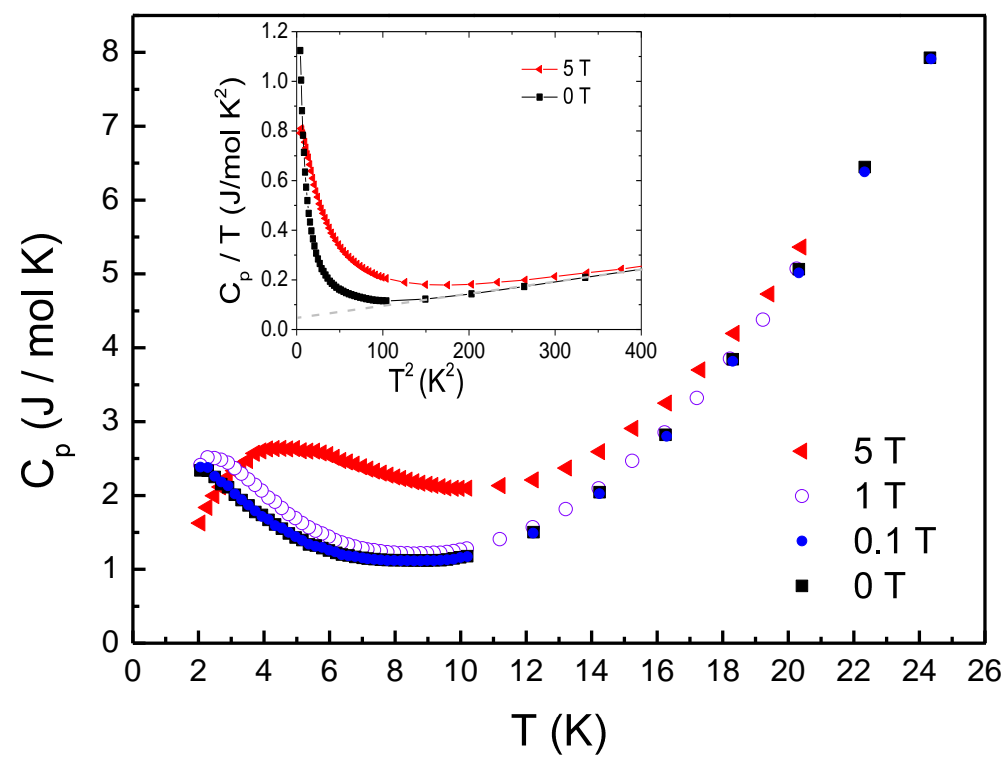

Fig. 4. Temperature dependence of the specific heat of $\mathrm{CeNiZnH}_{1.2}$ measured at $0,0.1,1$ and $5 \mathrm{~T}$. The inset presents the $C_{p} / T$ versus $T^{2}$ curve at 0 and $5 T$ with the linear fit $C_{p} / T=\gamma+\beta T^{2}$ in dotted line for zero magnetic field as mentioned in the text. 


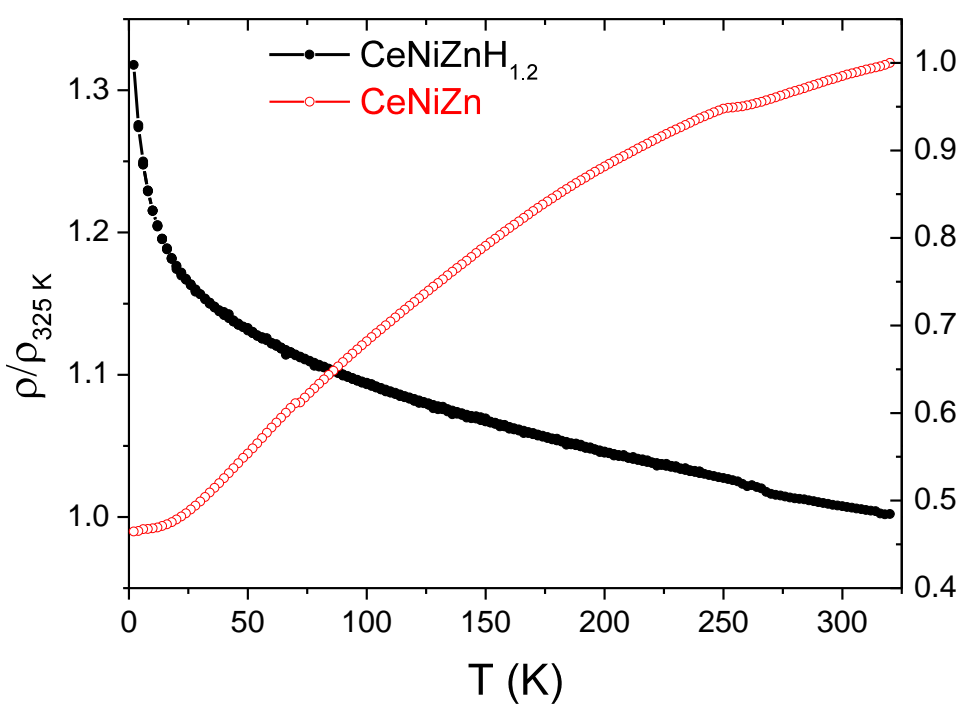

Fig. 5. Temperature dependence of the electrical resistivity of $\mathrm{CeNiZn}$ and $\mathrm{CeNiZnH}_{1.2}$, normalized to the value at $325 \mathrm{~K}$. 